\title{
A decade of systematic camera trapping in two strictly protected areas reveals the demography of a Eurasian lynx (Lynx lynx) population in Central Europe
}

\section{Stefano Palmero ( $\nabla$ st.palmero@gmail.com )}

University of Freiburg

\section{Elisa Belotti}

Šumava National Park Administration

\section{Luděk Bufka}

Šumava National Park Administration

\section{Martin Gahbauer}

Bavarian Forest National Park

Christoph Heibl

Bavarian Forest National Park

Joe Premier

Leibniz Institute for Zoo and Wildlife Research

Kirsten Weingarth

Technische Universität München

Marco Heurich

Bavarian Forest National Park

\section{Research Article}

Keywords: Large carnivores, Eurasian Lynx, population, management

Posted Date: February 26th, 2021

DOl: https://doi.org/10.21203/rs.3.rs-244765/v1

License: (1) (i) This work is licensed under a Creative Commons Attribution 4.0 International License. Read Full License 


\section{Abstract}

Large carnivores are crucial for ecosystems but are increasingly threatened by human persecution and habitat destruction. Successful conservation of this guild requires information on long-term population dynamics through the demographic surveys. We camera trapped Eurasian lynx between 2009 and 2018 in two strictly protected areas in the Bohemian Forest Ecosystem, estimating sex-specific demographic parameters using spatial capture-recapture (SCR) models as well as the relative abundance index of its prey species and a mesopredator seeking potential drivers of lynx population dynamics. Over 48677 trap nights, we detected 65 lynx individuals. Density increased to 1.31 and 2.39 individuals/100 km for open and closed population SCR models, respectively, with positive population growth rates. Survival rates were high (females $83 \%$, males $88 \%$ ) and per capita recruitment was low (females $13 \%$, males $9 \%$ ), indicating a low yearly population turnover. Reproductive parameters showed successful reproduction. Our results reveal the importance of the study area as host to a saturated population and key source for the potential lynx metapopulation. The observed increasing lynx number is most likely represented by dispersing individuals due to reduced mortality outside the protected areas as the number of reproducing females inside remained constant. In what is the first open population SCR study on lynx, we provide demographic parameters contributing to the development of model-based population viability forecasting and inform lynx management in the study area as well as in similar contexts.

\section{Introduction}

Large carnivores shape ecosystems through top-down control of herbivores and intraguild predation of mesocarnivores, triggering trophic cascades ${ }^{1}$. Their role is therefore crucial for the functioning of ecosystems. However, large carnivore conservation is particularly challenging. Carnivore lifestyles can generate conflicts with human activities ${ }^{2}$ and their wide-ranging behaviour necessitates complicated transboundary management ${ }^{3}$. Moreover, low densities and reproduction rates make these species vulnerable to the effects of human persecution ${ }^{4}$.

A deep understanding of demographic parameters such as abundance, density, survival and growth rate, is crucial for large carnivore conservation (e.g. Breitenmoser-Würsten et al., 2007), providing information on population dynamics and forming a basis for population forecasting using model-based predictions. However, these parameters can only be calculated over substantial time intervals, hence long-term data are required for meaningful studies ${ }^{6}$.

The use of camera traps as a wildlife monitoring tool has gained popularity in recent years (O'Connell et al., 2011). These non-invasive devices monitor different species simultaneously and avoid stressful animal immobilisation ${ }^{8}$. Camera traps can provide high-quality pictures enabling the identification of naturally marked animals ${ }^{9}$. This has led to their extensive use in combination with capture-recapture (CR) methods in demographic studies. Recently developed spatial capture-recapture (SCR) models present improvements over conventional non-spatial CR models in estimating demographic parameters because they incorporate spatial information (i.e. location of individuals and traps) ${ }^{10}$. Closed population SCR models assume 
demographic closure (i.e. constant population size) and are normally used to estimate abundance and density within one session ${ }^{10}$. More recent open population SCR models provide the advantage that they can be applied across multiple sessions providing further parameters such as survival, per capita recruitment and population growth rate (e.g. Chandler and Clark, 2014).

In the last century, the Eurasian lynx (Lynx lynx), was eradicated across Central Europe but, following legal protection, the establishment of protected areas and population reintroductions, have recolonised parts of its former range ${ }^{12}$. However, most of the reintroduced populations in Central Europe remain isolated and small in size ${ }^{12}$. As a typical example, the Bohemian-Bavarian-Austrian (BBA) population is classified as "endangered" and exhibits reduced genetic variability ${ }^{13}$. Müller et al. (2014) showed that the BohemianBavarian Forest (BBF) could serve as an important source area within a Central European lynx metapopulation although subadults cannot connect with neighbouring populations (i.e. German Harz, Czech Carpathian, and Austrian Alpine). The illegal killing has been implicated as the main mortality cause driving this population and the protected areas in the region as the crucial factor for its persistence ${ }^{4}$. The protection of source populations is proposed as a strategy for recovering species such as the tiger (Panthera tigris $)^{15}$. However, whether protected areas in Central Europe, with their limited size, can act as sources is poorly understood.

Here we conducted a demographic study on a Eurasian lynx (hereafter lynx) population in one of Central Europe's largest strictly protected areas, the Bohemian Forest Ecosystem (BFE). Studying this reintroduced population helps to improve the understanding of lynx ecology across its range since protected areas provide the opportunity to investigate population dynamics under low human disturbance. We systematically camera trapped lynx from 2009 to 2018 in the BFE. To our knowledge, this is the first demographic study on lynx comprising annual camera trapping over a decade and using open population SCR models. We expected higher densities of females since males have larger home ranges ${ }^{16}$. As lynx is a K-selected species, we expected generally high survival and low per capita recruitment rates. Specifically, we expected lower male survival rate because they generally take higher risks by getting closer to human activities due to high prey density ${ }^{17}$ and patrolling their larger home ranges. We expected an average litter size of about 2 kittens, in line with the optimum number shown for this species ${ }^{18}$. Finally, we used the relative abundance index (RAl) ${ }^{19}$ of lynx's main prey species and a mesopredator to explore potential influences of the prey base on lynx.

\section{Material And Methods}

\section{Study area}

The BBF is situated in Central Europe at the border between Austria, Czechia, and Germany, and includes two adjacent national parks: the Bavarian Forest National Park (BFNP) $\left(240 \mathrm{~km}^{2}\right)$ in Germany and the Šumava National Park (SNP) $\left(690 \mathrm{~km}^{2}\right)$ in Czechia (Fig. 1). The first is surrounded by the Bavarian Forest Natural Park $\left(3007 \mathrm{~km}^{2}\right)$ and the second by the Šumava Protected Landscape Area $\left(1000 \mathrm{~km}^{2}\right)$, together 
forming the BFE. Elevation ranges from 600 to 1456 m.a.s.I. and snow cover can persist for 5-8 months with greatest depths from January to March.

The area is covered by a mixed mountainous forest composed mainly of Norway Spruce (Picea abies), followed by European Beech (Fagus sylvatica) and Silver Fir (Abies alba) ${ }^{20}$ and hosts ungulate species such as roe deer (Capreolus capreolus), red deer (Cervus elaphus), wild boar (Sus scrofa) and moose (Alces alces) ${ }^{21}$. In the BFNP roe deer density ranges from 1.1 to 5 animals $/ \mathrm{km}^{2} 22$ and that of red deer was estimated as 1.56 animals $/ \mathrm{km}^{2}$ via coordinated counting at winter feeding stations. Densities of both species are higher in the SNP ${ }^{21}$. Wildlife control within both national parks is conducted by trained staff and is limited to red deer and wild boar, while roe deer, red deer and wild boar are killed by hunters outside their boundaries ${ }^{21}$.

The BBA lynx population originates from 5-10 individuals illegally reintroduced in the 1970s followed by an official reintroduction of 17 individuals (11 males and 6 females) in the 1980s (Wölfl et al., 2001). Population size and density were recently estimated as $97-143^{24}$ and $0.4-0.9$ individuals $/ 100 \mathrm{~km}^{2} 25$, respectively. This predator is legally protected in all three countries but illegal killing still occurs ${ }^{4}$. The main prey species of lynx is roe deer followed by red deer ( $80 \%$ and $17 \%$ of kills, respectively) ${ }^{26}$.

\section{Camera trap monitoring}

Data were collected between 2009 and 2018. The monitoring design was developed for lynx but also provided data on other species. The spatial organisation of camera traps was designed by Weingarth et al. (2012). This consisted of a $2.7 \times 2.7 \mathrm{~km}$ grid (Fig. 1) maximising detection probability and avoiding gaps that might include female home ranges, i.e. a minimum of $122 \mathrm{~km}^{2}$ estimated in the study area with radiotelemetry ${ }^{27}$, where camera trap sites were located in every second cell along forest paths, roads and trails. The grid occupied the entire BFNP and two-thirds of the SNP. Since individual identification requires highquality pictures of both animal flanks, most sites included two opposing cameras (Cuddeback ${ }^{\circledR}$ ) with white flash. In the BFNP, camera traps functioned almost constantly for 10 "lynx years". A lynx year is defined as the period from 01/05 to 30/04 since kittens are mostly born in May and leave the mother in April of the following year ${ }^{28}$. In the SNP, most of the camera traps were only active from mid-September to the end of December. Camera trapping sites were moved slightly at the beginning of each session and changed in number.

We identified lynx individuals from images by comparing their unique coat patterns. Sex was determined by observing females with kittens or the genital area of the animal. Age was difficult to assess except for individuals first photographed as kittens. Therefore, we followed Weingarth et al. (2012) and assigned animals into two categories referring to their status: "juvenile" and "independent". The juvenile category included individuals $<1$-year-old, i.e. kittens detected with their mother. This category was discarded from the SCR analysis because of the high mortality of kittens (e.g. Andrén et al., 2002). The independent category included all individuals $>1$-year-old (i.e. subadults and adults) and individuals of unknown age but with proof of independence. All individuals of unknown status were discarded from analyses.

\section{Demography of lynx}


Demography was investigated using both open and closed population SCR model frameworks (Supplementary Table S1). Although the former method allows estimation of the full range of demographic parameters, we included the latter for backward compatibility with previous studies conducted on lynx in Europe using closed population SCR models (e.g. Gimenez et al., 2019), as well as for comparison of both methods within one study.

Following Weingarth et al. (2015), we selected a time frame of 100 days from 15/09 to 24/12 of every year ensuring demographic closure as a primary period. We combined all primary periods according to a classical "robust design" ${ }^{33}$, and thus performed open population SCR analysis. We defined one secondary period as one day and restricted the number of detections to at most one per site in any secondary period in line with a Bernoulli distribution, thereby reducing temporal autocorrelation. Our study included ten primary periods with 100 secondary periods each. The SCR method assumes the baseline detection probability $g_{0}$ of any individual declines with the distance from its theoretical home range centre, the detection function scale $\sigma$, in the state space $S$, which should be at least $3 \sigma,{ }^{10}$. We, therefore, created a state-space mask with a continuous buffer of $18,000 \mathrm{~km}^{2}$ around camera traps based on results of preliminary closed SCR analyses (i.e. $\sigma \sim 3.5-4 \mathrm{~km}$ ). We used the density-independent population growth model in a Bayesian framework developed by ${ }^{11}$ and an adaptation to sex-specificity of the demographic parameters by Satter et al. (2019). Using the R package "OpenPopSCR" 35 , we ran 10 pooled chains for 25,000 Markov chain Monte Carlo iterations each with an augmented observed population size of 400 individuals, i.e. much greater than the overall number of independent individuals detected across all primary periods. We estimated sexspecific density and used a Markov activity centre relocation type ${ }^{36}$ between primary periods to estimate male and female yearly survival and per capita recruitment separately from emigration and immigration, respectively ${ }^{37}$. The yearly movement between primary periods was estimated for combined males and females. Per capita recruitment estimates indicated the number of individuals per sex class added to total abundance each year. Sex-specific population growth rate and sex ratio were estimated as derived parameters. The estimates of the latter indicated the probability of any individual to be a female. All point estimates were obtained using posterior modes and interval estimates were calculated through $95 \%$ highest posterior density (HPD) intervals using the $2.5 \%$ and $97.5 \%$ quantiles of the posterior distribution ${ }^{10}$.

Closed population SCR models in a maximum likelihood framework were fitted in the R package "secr" (Efford, 2019). We defined one sampling occasion as five days ${ }^{9}$ and used detector type proximity (Efford, 2019) according to a Bernoulli distribution to estimate the combined density of males and females. We used a buffer of $13^{\prime} 000 \mathrm{~km}^{2}$ according to secr buffer predictor to create state-space masks with continuous and discrete habitat. For the latter, we followed Rovero and Zimmermann (2016) and created a habitat suitability mask excluding highly unsuitable patches ${ }^{27}$. Sex was tested as a covariate on $g_{0}$ and $\sigma$. We followed Akaike's Information Criterion corrected for small sample sizes (AICC) to determine the best model for our data and kept those with $\triangle \mathrm{AICc}<2$ for model-averaging ${ }^{40}$. Statistical significances were evaluated using the $95 \%$ confidence intervals $(\mathrm{Cl})$.

We calculated generation time as the mean age of reproducing females (i.e. females with kittens) at their first recorded litter including only those of known age (assessed via all recaptures), while all known 
reproducing females were included for calculating average litter size. Regarding the latter, we included all available data referring to complete lynx years, since some kittens are detected later in January/February. Finally, we included all the independent individuals of known age and sex detected during the primary periods for investigating the age distribution.

\section{Relative abundance index}

When species cannot be individually identified, camera trapping data can be used to calculate abundance indices (O'Brien, 2011). The relative abundance index (RAI) (O'Brien et al., 2003), which expresses the number of captures per monitoring day, is the most widely used (O'Brien, 2011).

This aspect of the study was conducted in the BFNP only ( $n=29-31$ camera trapping sites). The session length was matched to that of SCR analysis. We identified and included lynx's main prey species, i.e. roe deer and red deer, and red fox (Vulpes vulpes). To avoid temporal autocorrelation, we defined capture events with a threshold of 10 minutes ${ }^{39}$ and bootstrapped the RAl calculation by randomly selecting one camera trap per site (5000 replicates) to reduce camera and site capture biases

\section{Use of experimental animals}

No animals were used or handled in the study.

\section{Results}

\section{Camera trap monitoring}

We detected 65 unique independent individuals ( 25 males, 28 females and 12 individuals of unknown sex) in a total of 48,677 trap nights (Table 1). The standardised session length of 100 days was not achieved in all primary periods, especially in the earlier ones, due to technical problems such as camera trap failure, risk of theft or snowfall. We observed increasing juveniles and independent individuals including males, females and individuals of unknown sex while the number of reproducing females (i.e. females with kittens) remained quite stable. The age status was determined in most cases except for few individuals in the first and third sessions. We were able to confirm mortality causes of some detected individuals in the vicinity of the study area, which showed an increase in traffic accidents and occasional illegal killing. In particular, traffic accidents killed five independent individuals and two juveniles in the BFNP, while illegal killing affected two independent individuals and one juvenile of unknown sex outside its boundaries, in Germany.

Table 1 Summary of the available information about lynx obtained every primary period, including the number of independent females and reproducing females (with kittens), males, individuals of unknown sex, juveniles, individuals of unknown status, camera trapping sites, effective trap nights and documented mortality cases with known causes. 


\begin{tabular}{|c|c|c|c|c|c|c|c|c|c|c|}
\hline \multirow[t]{3}{*}{ Session } & \multicolumn{6}{|l|}{ Status } & \multirow{3}{*}{$\begin{array}{l}\text { Camera } \\
\text { trapping } \\
\text { sites }\end{array}$} & \multirow{3}{*}{$\begin{array}{l}\text { Trap } \\
\text { nights }\end{array}$} & \multirow{2}{*}{\multicolumn{2}{|c|}{$\begin{array}{l}\text { Known mortality } \\
\text { causes }\end{array}$}} \\
\hline & \multicolumn{4}{|c|}{ Independent } & \multirow[t]{2}{*}{ Juvenile } & \multirow[t]{2}{*}{ Unknown } & & & & \\
\hline & $\begin{array}{l}\text { Female } \\
\text { (with } \\
\text { kittens) }\end{array}$ & Male & $\begin{array}{l}\text { Unknown } \\
\text { sex }\end{array}$ & Total & & & & & $\begin{array}{l}\text { Traffic } \\
\text { accidents }\end{array}$ & $\begin{array}{l}\text { Illegal } \\
\text { killing }\end{array}$ \\
\hline 2009 & $6(4)$ & 3 & 0 & 9 & 8 & 3 & 55 & 1728 & 0 & 0 \\
\hline 2010 & $6(4)$ & 6 & 1 & 13 & 8 & 0 & 62 & 3813 & 0 & 0 \\
\hline 2011 & $8(3)$ & 7 & 1 & 16 & 5 & 4 & 66 & 4124 & 0 & 0 \\
\hline 2012 & $7(3)$ & 5 & 1 & 13 & 5 & 0 & 31 & 2621 & 0 & 1 \\
\hline 2013 & $8(6)$ & 7 & 1 & 16 & 8 & 0 & 66 & 5885 & 0 & 1 \\
\hline 2014 & $9(6)$ & 8 & 0 & 17 & 9 & 0 & 65 & 6151 & 1 & 0 \\
\hline 2015 & $11(2)$ & 10 & 0 & 21 & 5 & 0 & 64 & 6022 & 1 & 1 \\
\hline 2016 & $12(5)$ & 11 & 3 & 26 & 11 & 0 & 65 & 5964 & 2 & 0 \\
\hline 2017 & $11(4)$ & 14 & 3 & 28 & 6 & 0 & 69 & 5957 & 2 & 0 \\
\hline 2018 & $11(7)$ & 13 & 1 & 25 & 15 & 0 & 69 & 6412 & 1 & 0 \\
\hline
\end{tabular}

The combined density of independent males and females estimated for each primary period using open population SCR models ranged from 0.68 (95\% HPD intervals $0.48-1.07$ ) to 1.31 (95\% HPD intervals 1.031.76) individuals $/ 100 \mathrm{~km}^{2}$ while, as expected, sex-specific density estimates were on average higher for females (Fig. 2). However, the overlapping 95\% HPD intervals suggest there was no significant difference between sexes.

The parameter posterior modes (Table 2) of the yearly baseline detection probability $g_{0}$ were equal between sexes. The yearly capita recruitment was higher for females. Contrary to our expectation, the yearly survival rate was higher for males. As expected, males showed a higher yearly detection function scale $\sigma$, due to larger home ranges. However, considering the overlap of 95\% HPD intervals, none of the parameters indicated a significant difference between sexes.

Table 2 Posterior modes and 95\% highest posterior density (HPD) intervals of open population spatial capture-recapture (SCR) model referring to male (M) and female (F) lynx yearly baseline detection probability $g_{0}$, detection function scale $\sigma(\mathrm{km})$, survival rate and per capita recruitment. Per capita recruitment indicates the number of individuals of each sex added per year per total abundance. The yearly movement $(\mathrm{km})$ was calculated for combined (C) sexes. 


\begin{tabular}{lllll}
\hline Parameter & \multicolumn{2}{l}{ Sex } & Estimate & \multicolumn{2}{l}{ 95\% HPD Intervals } \\
\cline { 3 - 5 } & & & Lower & Upper \\
\hline Detection probability & $\mathrm{M}$ & 0.01 & 0.01 & 0.01 \\
& $\mathrm{~F}$ & 0.01 & 0.01 & 0.02 \\
\hline Detection function scale & $\mathrm{M}$ & 4.09 & 3.79 & 4.37 \\
& $\mathrm{~F}$ & 3.97 & 3.66 & 4.32 \\
\hline Survival rate & $\mathrm{M}$ & 0.88 & 0.79 & 0.96 \\
\cline { 2 - 5 } & $\mathrm{F}$ & 0.83 & 0.72 & 0.91 \\
\hline Per capita recruitment & $\mathrm{M}$ & 0.09 & 0.04 & 0.14 \\
\cline { 2 - 5 } & $\mathrm{F}$ & 0.13 & 0.07 & 0.19 \\
\hline Movement & $\mathrm{C}$ & 4.95 & 4.23 & 5.56 \\
\hline
\end{tabular}

The realised population growth rate was 1.06 (range 1.01-1.10), with 1.06 (range 0.96-1.12) for males and 1.05 (range 1.00-1.14) for females. The probability of any individual to be a female was almost stable over years ranging from 0.50 (95\% HPD intervals $0.35-0.65)$ to 0.54 (95\% HPD intervals $0.41-0.67$ ), meaning the sex ratio was slightly skewed towards females, even if not significantly.

Concerning closed population SCR models, estimates of density ranged from 1.02 (SE 0.28) to 2.39 (SE 0.7 ) individuals/100 km² (Supplementary Table S2; Supplementary Table S3) and were higher compared to open population SCR models.

Regarding reproductive parameters, we included 13 and 21 reproducing females for calculating generation time (2.64) and average litter size (1.97), respectively (Supplementary Table S4). As expected, the latter was close to the lynx optimum number.

The age distribution pyramid included 24 independent individuals of known age and sex and was slightly female-biased in size (15 females vs 9 males) (Supplementary Figure S1). The oldest individual of known age was a 10-year-old male individual. The number of females at each age was equal to or higher than that of males except for ages 8-10.

\section{Relative abundance index}

The RAl of red fox ranged from 0.07 (SD 0.01) to 0.14 (SD 0.02), that of red deer from 0.01 (SD 0.00) to 0.07 $(S D 0.01)$ and that of roe deer from $0.00(S D 0.00)$ to 0.04 (SD 0.01) (Fig. 3). Fox abundance increased from 2009 to 2014 and decreased in the remaining years. Red deer and roe deer slightly increased until 2014, after which the former almost doubled while the latter decreased to earlier values.

\section{Discussion}

Our results prove the number of independent lynx in the BBF has slightly increased over the past decade with a positive population growth rate. Survival rates were high and per capita recruitment was low indicating a low yearly population turnover. Reproductive parameters showed successful reproduction occurring every year, confirming the area represents a key source for the surrounding landscape. 
Compared to results of closed population SCR studies on lynx conducted across Europe, density estimates of both open (0.68-1.31 individuals $/ 100 \mathrm{~km}^{2}$ ) and closed population SCR models (1.02-2.39 individuals $/ 100 \mathrm{~km}^{2}$ ) are among the highest. Gimenez et al. (2019) camera trapped lynx in the French Jura and Vosges Mountains between 2011 and 2016 and found densities ranging from 0.24 to 0.91 individuals $/ 100 \mathrm{~km}^{2}$. Pesenti and Zimmermann (2013) conducted a camera trapping survey in winter 2007-2008 and 2009-2010 in the north-western Swiss Alps estimating densities of 1.47 and 1.38 individuals $/ 100 \mathrm{~km}^{2}$ respectively. In the southern Jura Mountains from December 2017 to February 2018, 42 found a density of 3.48 individuals $/ 100 \mathrm{~km}^{2}$ of suitable habitat as the highest across all reference areas in Switzerland.

The yearly baseline detection probability $g_{0}$ was equal between sexes (Table 2). Although males are generally more active patrolling larger home ranges, females with kittens hunt at a higher rate resulting in augmented activity ${ }^{43}$. We found a higher yearly detection function scale $\sigma$ for males (Table 2), corresponding to larger home ranges, which in line with, e.g., Schmidt et al. (1997) and common in felids (e.g. Satter et al., 2019) with however no significant difference between sexes.

Open population SCR models in a Bayesian framework allowed us to separate survival from emigration and recruitment from immigration. Although this approach is still under development due to large camera trapping array requirements ${ }^{37}$, it is reasonable to assume that true survival is at least as high as the value we estimated when the underestimation due to the inclusion of emigration is considered. Our combined yearly survival rates for subadults and adults (population mean $=85 \%$ ) are among the highest observed for lynx in Central Europe. This is because our estimates come from strictly protected areas where animals have a higher chance to survive. However, the only values available for comparison are from telemetry studies, which are generally conducted with smaller sample sizes because of high-cost devices but allow to track animals' fates. In Switzerland, Breitenmoser-Würsten et al. (2007) found an overall survival rate of $76 \%$ for adults and $53.3 \%$ for subadults. In Poland, the combined survival rate of subadults and adults was $63 \%{ }^{44}$. In three Scandinavian study sites, Andrén et al. (2002) found higher survival rates for subadults (70, 77 and $71 \%$ ) and adults (87, 91 and 84\%), likely due to lower human-related mortality throughout adulthood. Against our expectations, the survival rate was higher for males. This was due to a higher overall number of male apparent survival events, which consist of the number of consecutive detections over years including gaps during which the animal was alive but eluded detection. However, we did not find any strong difference in survival rates between sexes. A similar open population SCR study, conducted on a low-density ocelot population in Belize, also showed no significant differences in sex-specific survival, despite a survival rate of 0.86 for females and 0.78 for males (Satter et al. 2019). The authors suggested the statistical power was not enough to detect significant differences between sexes in these parameters, although they were able to determine sex for a large number of adult ocelots $(n=322)$.

Camera trapping does not allow assessment of the fates of all disappearing individuals. While our findings show increasing vehicle collisions in recent years (Table 1), we could not assess the actual impact of illegal killing since carcasses are seldom found and it only occurs outside the protected area, as confirmed by the high survival rates found inside it. Illegal killing still represents one of the main lynx mortality causes 
Europewide, responsible for $32 \%$ of known lynx death in Switzerland ${ }^{5}, 46 \%$ in Scandinavia ${ }^{45}$ and $71 \%$ in Poland ${ }^{44}$. In the vicinity of our study area, a high poaching rate has been suggested by a modelling approach ${ }^{4}$.

We did not detect a significant difference in per capita recruitment between sexes (Table 2), similar again to Satter et al. (2019). Our results of generation time (2.64 years) and the average litter size of 1.97 (range 13 ) were close to those of other studies in Europe. It was proposed based on data of the Scandinavian population that lynx displays a common optimal litter size related to fitness rather than ecological conditions ${ }^{18}$. In four areas of Scandinavia, Nilsen et al. (2012) investigated reproductive parameters and found a higher proportion of reproductive females $\geq 3$ years of age than females of just 2 years of age, while average litter size was not significantly different (mean across sites $=2.10$ ). Similar results were found in the south-central Scandinavian Peninsula where the yearly reproduction probability was 0.81 for $\geq$ 3 years old females and 0.77 for 2 years old females, while average litter size was 2.32 (range 1-4) ${ }^{47}$. In Switzerland, the average litter size was $2.00^{5}$. We were not able to assess the proportion of reproductive females because sex was not determined for all detected individuals.

The maximum age observed in the study area was 10 years, which was constrained by the study duration. In Switzerland, Breitenmoser-Würsten et al. (2007) found individuals 14-15 years of age through telemetry. Age cannot always be determined through camera trapping. As such, individuals already classified as independent in the first session reached higher values than those we observed, even if their exact age remained unknown.

According to the RAl results, roe deer abundance on the German side remained stable despite the ban on population control of this species in 2012. Contrastingly, the red deer population increased (Fig. 3). This is consistent with the top-down limitation of roe deer abundance by lynx in the study site (e.g. Heurich et al., 2012), with little influence on that of red deer. This finding might indicate that a higher consumption rate of roe deer was not possible in the area. However, especially male lynx might take advantage of increasing red deer numbers as they hunt calves and yearlings of that species ${ }^{26}$. The observed abundance decrease in red fox could be due to intraguild predation as it coincides with increasing in lynx numbers, as reported in Scandinavia (e.g. Elmhagen and Rushton, 2007). However, considering that in the study area the red fox is only $1 \%$ of lynx kills ${ }^{26}$, other factors such as food availability and diseases are likely driving red fox dynamics. Although RAl can be affected by biases attributed to changes in detection probability ${ }^{50}$, we believe this method well represented the abundance trend of the species in question since the study design was uniform throughout the monitoring period.

For lynx, we found positive population growth rates, high survival rates and low per capita recruitment resulting in a low yearly population turnover. A stable number of reproducing females and stable prey base indicate carrying capacity for lynx in the study area has already been reached. Therefore, the increasing number of independent lynx most likely comprises dispersing individuals crossing the study area, a few of which settle replacing disappearing resident individuals. This indicates that lynx distribution has changed rather outside the study area. 
Contemporary assessments of the BBA lynx population, based on coordinated transboundary camera trapping within an area of $13,000 \mathrm{~km} 2$, show a slightly positive population trend and confirm lynx presence and reproduction in the surroundings of the study area ${ }^{24}$. In conclusion, the changes we observed could be related to locally decreasing poaching possibly as a result of both law enforcement and intensive long-term campaigns aiming to raise acceptance in the wake of high-profile poaching incidents.

Our study stresses open population SCR models can provide a wider range of demographic parameters useful for lynx monitoring than closed population SCR models. Data gaps affecting the earlier sessions possibly resulted in biased estimates, especially regarding those of closed population SCR models in a maximum likelihood form (Supplementary Table S2). Bayesian methods can better deal with the problem of incomplete detection because they produce posterior distributions of the demographic parameters incorporating the uncertainty resulting from data gaps by using the information deriving from other primary periods ${ }^{11}$. This highlights the robustness of this method, which we recommend in future studies and monitoring, especially with incomplete detections. Nonetheless, closed population SCR models still represent a reliable tool for abundance and density assessments (e.g. Gimenez et al., 2019).

\section{Conclusions}

The protected areas in focus appear to host an important population core with high density and survival rate and low yearly turnover. As proposed for other large carnivores ${ }^{15}$, protected areas should be considered as strategic for lynx recovery across its range. However, our results clearly show that the suitability of the surrounding landscapes is fundamental for long term population viability, as the constant number of reproducing females throughout the monitoring period indicates lynx reached carrying capacity in the study area of two adjacent National Parks. This view is also supported by a stable prey base. Additionally, conservation of species with large spatial requirements cannot rely on protected areas alone especially when considering long term genetic viability ${ }^{51}$.

Our study revealed important demographic parameters of lynx that can be used for population forecasting across broad spatial contexts, thus improving conservation and management plans. Finally, we stress the importance of long-term systematic monitoring as a basis for the understanding of population dynamics of this and other large carnivore populations.

\section{Declarations}

\section{Conflict of interests}

The authors declare that they have no known competing financial interests or personal relationships that could have appeared to influence the work reported in this paper.

\section{Authors contribution}


This submission represents original work carried out by the authors. All authors have contributed substantially to the manuscript and have approved the manuscript and agree to its submission.

\section{Acknowledgements}

The study was funded by the German Academic Exchange Service (DAAD) and allowed by the Administrations of both the BFNP and SNP. We thank Ben Augustine and Murray Efford who shared R packages and helped with SCR analyses. We kindly thank all the colleagues of both the BFNP and the SNP who facilitated the study. In particular, we thank Nicolò Borgianni who helped with part of the analyses.

\section{References}

1. Ripple, W. J. et al. Status and Ecological Effects of the World's Largest Carnivores. Science.343, 1241484-1241484 (2014).

2. Treves, A. \& Karanth, K. U. Human-Carnivore Conflict and Perspectives on Carnivore Management Worldwide. Conserv. Biol.17, 1491-1499 (2003).

3. Linnell, J. D. C. \& Boitani, L. Building biological realism into wolf management policy: the development of the population approach in Europe. Hystrix Ital. J. Mammal.23, (2011).

4. Heurich, M. et al. Illegal hunting as a major driver of the source-sink dynamics of a reintroduced lynx population in Central Europe. Biol. Conserv.224, 355-365 (2018).

5. Breitenmoser-Würsten, C., Vandel, J. M., Zimmermann, F. \& Breitenmoser, U. Demography of lynx Lynx lynx in the Jura Mountains. Wildl. Biol.13, 381-392 (2007).

6. Clutton-Brock, T. \& Sheldon, B. C. Individuals and populations: the role of long-term, individual-based studies of animals in ecology and evolutionary biology. Trends Ecol. Evol.25, 562-573 (2010).

7. O’Connell, A., Nichols, J. D. \& Karanth, K. U. Camera traps in animal ecology: Methods and analyses. (2011). doi:10.1007/978-4-431-99495-4.

8. Noss, A. J. et al. A Camera Trapping and Radio Telemetry Study of Lowland Tapir (Tapirus terrestris) in Bolivian Dry Forests. 12,9(2003).

9. Karanth, K. U. \& Nichols, J. D. ESTIMATION OF TIGER DENSITIES IN INDIA USING PHOTOGRAPHIC CAPTURES AND RECAPTURES. 79,11(1998).

10. Spatial capture-recapture(Elsevier, 2014).

11. Chandler, R. B. \& Clark, J. D. Spatially explicit integrated population models. Methods Ecol. Evol.5, $1351-1360$ (2014).

12. Kaczensky, P. et al. Status, Management and Distribution of Large Carnivores - Bear, Lynx, Wolf and Wolverine in Europe. Part 1.IUCNSSC Large Carniv. Initiat. Eur.(2013).

13. Bull, J. K. et al. The effect of reintroductions on the genetic variability in Eurasian lynx populations: the cases of Bohemian-Bavarian and Vosges-Palatinian populations. Conserv. Genet.17, 1229-1234 (2016). 
14. Müller, J. et al. Protected areas shape the spatial distribution of a European lynx population more than 20 years after reintroduction. Biol. Conserv.177, 210-217 (2014).

15. Walston, J. et al. Bringing the Tiger Back from the Brink-The Six Percent Solution. PLoS Biol.8, e1000485 (2010).

16. Schmidt, K., Jędrzejewski, W. \& Okarma, H. Spatial organization and social relations in the Eurasian Iynx population in Bialowieza Primeval Forest, Poland. Acta Theriol. (Warsz.).42, 289-312 (1997).

17. Bunnefeld, N., Linnell, J. D. C., Odden, J., van Duijn, M. A. J. \& Andersen, R. Risk taking by Eurasian lynx (Lynx lynx) in a human-dominated landscape: effects of sex and reproductive status. J. Zool.0, 060606025751009-060606025751009 (2006).

18. Gaillard, J. M., Nilsen, E. B., Odden, J., Andrén, H. \& Linnell, J. D. C. One size fits all: Eurasian lynx females share a common optimal litter size. J. Anim. Ecol.83, 107-115 (2014).

19. O'Brien, T. G., Kinnaird, M. F. \& Wibisono, H. T. Crouching tigers, hidden prey: Sumatran tiger and prey populations in a tropical forest landscape. Anim. Conserv.6, 131-139 (2003).

20. Cailleret, M., Heurich, M. \& Bugmann, H. Reduction in browsing intensity may not compensate climate change effects on tree species composition in the Bavarian Forest National Park. For. Ecol. Manag.328, 179-192 (2014).

21. Heurich, M. et al. Cover or Protection: What Shapes the Distribution of Red Deer and Roe Deer in the Bohemian Forest Ecosystem? PLOS ONE.10, e0120960 (2015). Country

22. van Beeck Calkoen, S. T. S. et al. The blame game: Using eDNA to identify species-specific tree browsing by red deer (Cervus elaphus) and roe deer (Capreolus capreolus) in a temperate forest. For. Ecol. Manag.451, 117483 (2019).

23. Wölfl, M., Heurich, M., Habel, H., Huber, T. \& Poost, W. Distribution and status of lynx in the border region between Czech Republic, Germany and Austria.14.

24. Mináriková, T. et al. Lynx Monitoring Report for Bohemian-Bavarian-Austrian lynx population for Lynx year 2017. 17 pp. Report prepared within the 3Lynx Project, funded by INTERREG Central Europe. 17 (2019).

25. Weingarth, K. et al. First estimation of Eurasian lynx (Lynx lynx) abundance and density using digital cameras and capture-recapture techniques in a German national park.Anim. Biodivers. Conserv.11 (2012).

26. Belotti, E. et al. Patterns of Lynx Predation at the Interface between Protected Areas and Multi-Use Landscapes in Central Europe. PLOS ONE.10, e0138139 (2015).

27. Magg, N. et al. Habitat availability is not limiting the distribution of the Bohemian-Bavarian lynx Lynx lynx population. Oryx.50, 742-752 (2016).

28. Zimmermann, F., Breitenmoser-Würsten, C. \& Breitenmoser, U. Natal dispersal of Eurasian lynx (Lynx lynx) in Switzerland. J. Zool.267, 381 (2005).

29. Andrén, H. et al. Estimating total lynx Lynx lynx population size from censuses of family groups. Wildl. Biol.8, 299-306 (2002). 
30. Gimenez, O. et al. Spatial density estimates of Eurasian lynx (Lynx lynx) in the French Jura and Vosges Mountains. Ecol. Evol.9, 11707-11715 (2019).

31. Pesenti, E. \& Zimmermann, F. Density estimations of the Eurasian lynx (Lynx lynx) in the Swiss Alps. J. Mammal.94, 73-81 (2013).

32. Weingarth, K. et al. Hide and seek: extended camera-trap session lengths and autumn provide best parameters for estimating lynx densities in mountainous areas. Biodivers. Conserv.24, 2935-2952 (2015).

33. Pollock, K. H. A Capture-Recapture Design Robust to Unequal Probability of Capture. J. Wildl. Manag.46, 752 (1982).

34. Satter, C. B., Augustine, B. C., Harmsen, B. J., Foster, R. J. \& Kelly, M. J. Sex-specific population dynamics of ocelots in Belize using open population spatial capture-recapture.Ecosphere10, (2019).

35. Augustine, B. benaug/OpenPopSCR. (2019).

36. Schaub, M. \& Royle, J. A. Estimating true instead of apparent survival using spatial Cormack-JollySeber models. Methods Ecol. Evol.5, 1316-1326 (2014).

37. Ergon, T. \& Gardner, B. Separating mortality and emigration: modelling space use, dispersal and survival with robust-design spatial capture-recapture data. Methods Ecol. Evol.5, 1327-1336 (2014).

38. Efford, M. secr 3.2 - spatially explicit capture-recapture in R.20.

39. Rovero, F. \& Zimmermann, F. Camera Trapping for Wildlife Research(Pelagic Publishing Ltd, 2016).

40. Burnham, K. P., Anderson, D. R. \& Burnham, K. P. Model selection and multimodel inference: a practical information-theoretic approach(Springer, 2002).

41. O'Brien, T. G. \& Abundance Density and Relative Abundance: A Conceptual Framework. in Camera Traps in Animal Ecology (eds. O'Connell, A. F., Nichols, J. D. \& Karanth, K. U.) 71-96(Springer Japan, 2011). doi:10.1007/978-4-431-99495-4_6.

42. Zimmermann, F. et al. Abondance et densité du lynx dans le Sud du Jura suisse: estimation par capture-recapture photographique dans le sous-compartiment la, durant l'hiver 2017-2018 23.23(2018).

43. Heurich, M. et al. Activity Patterns of Eurasian Lynx Are Modulated by Light Regime and Individual Traits over a Wide Latitudinal Range. PLOS ONE.9, e114143 (2014).

44. Jedrzejewski, W. et al. Population dynamics (1869-1994), demography, and home ranges of the lynx in Bialowieza Primeval Forest (Poland and Belarus). Ecography.19, 122-138 (1996).

45. Andrén, H. et al. Survival rates and causes of mortality in Eurasian lynx (Lynx lynx) in multi-use landscapes. Biol. Conserv.131, 23-32 (2006).

46. Nilsen, E. B., Linnell, J. D. C., Odden, J., Samelius, G. \& Andrén, H. Patterns of variation in reproductive parameters in Eurasian lynx (Lynx lynx). Acta Theriol. (Warsz.).57, 217-223 (2012).

47. López-Bao, J. V. et al. Eurasian lynx fitness shows little variation across Scandinavian humandominated landscapes. Sci. Rep.9, 8903 (2019).

48. Heurich, M. et al. Survival and causes of death of European Roe Deer before and after Eurasian Lynx reintroduction in the Bavarian Forest National Park. Eur. J. Wildl. Res.58, 567-578 (2012). 
49. Elmhagen, B. \& Rushton, S. P. Trophic control of mesopredators in terrestrial ecosystems: top-down or bottom-up? Ecol. Lett.10, 197-206 (2007).

50. Sollmann, R., Mohamed, A., Samejima, H. \& Wilting, A. Risky business or simple solution - Relative abundance indices from camera-trapping. Biol. Conserv.159, 405-412 (2013).

51. Linnell, J. D. C., Kaczensky, P., Wotschikowsky, U., Lescureux, N. \& Boitani, L. Framing the relationship between people and nature in the context of European conservation: Relationship Between People and Nature. Conserv. Biol.29, 978-985 (2015).

\section{Figures}

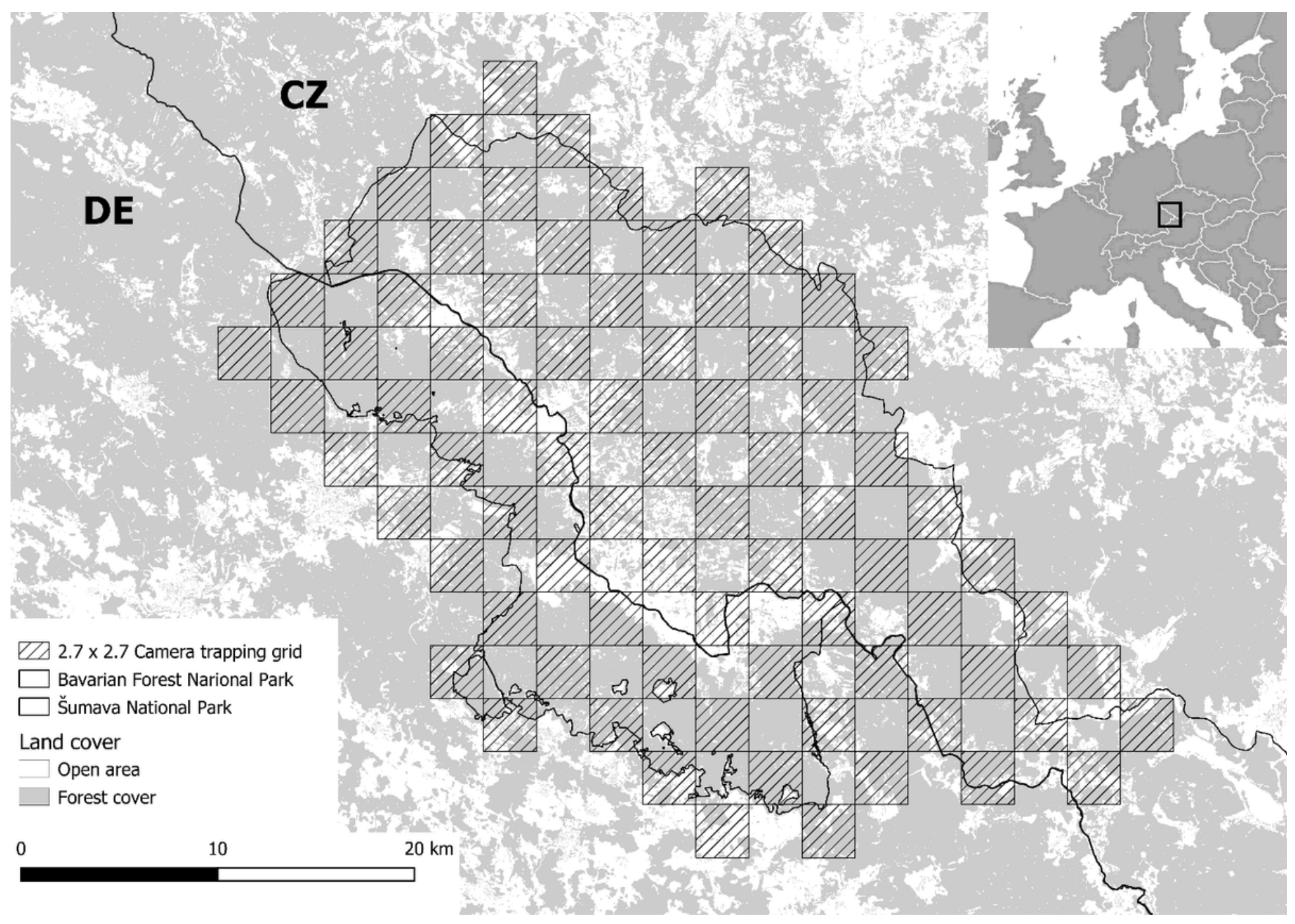

Figure 1

Map of the study area with forest coverage including the Bavarian Forest National Park (BFNP) on the German side (DE), the Šumava National Park (SNP) on the Czech side (CZ) and the $2.7 \times 2.7 \mathrm{~km}$ camera trapping grid in which sites were located in every second cell. 


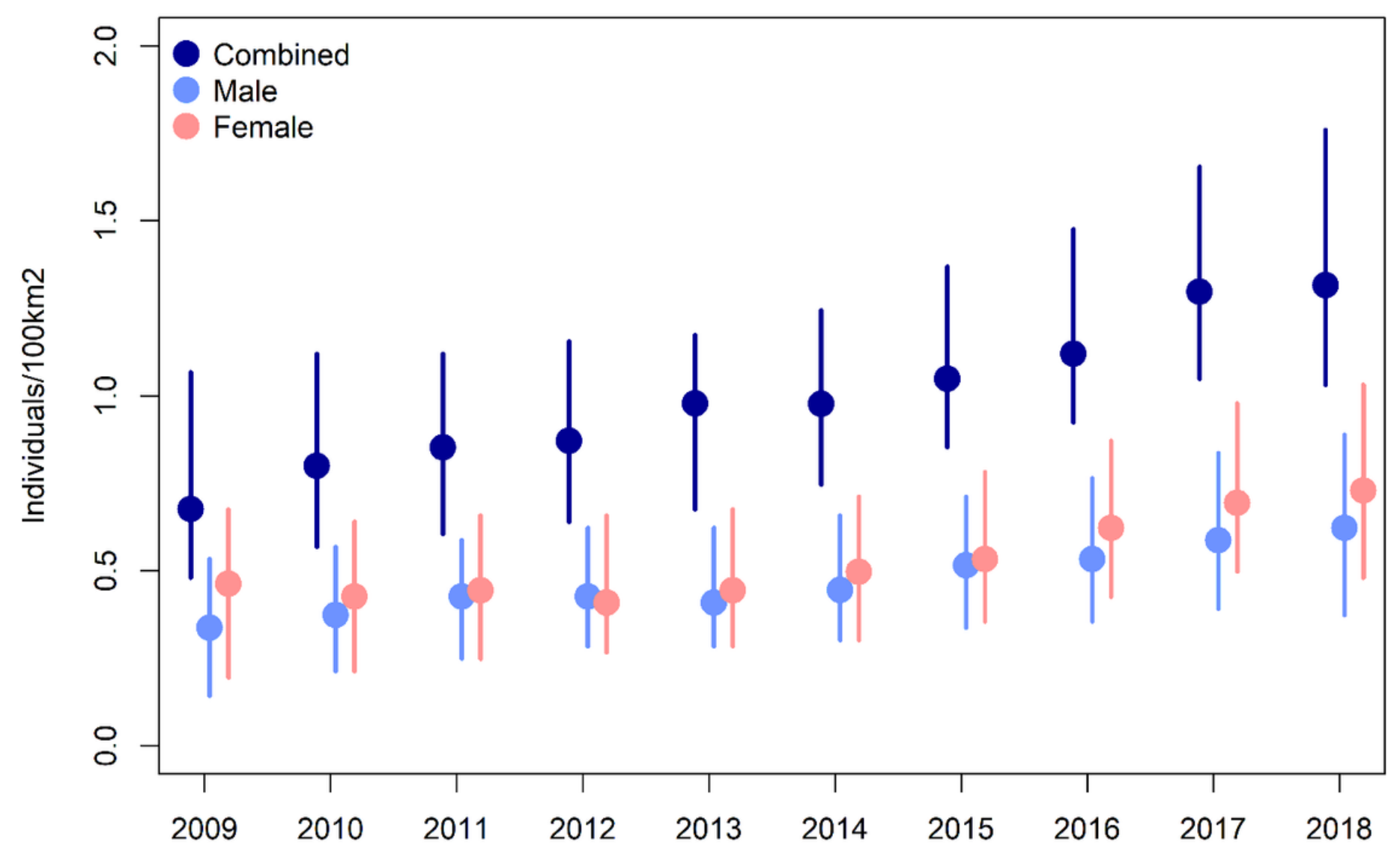

Figure 2

Posterior modes and 95\% highest posterior density (HPD) intervals of open population spatial capturerecapture (SCR) models referring to combined, male and female lynx densities. 


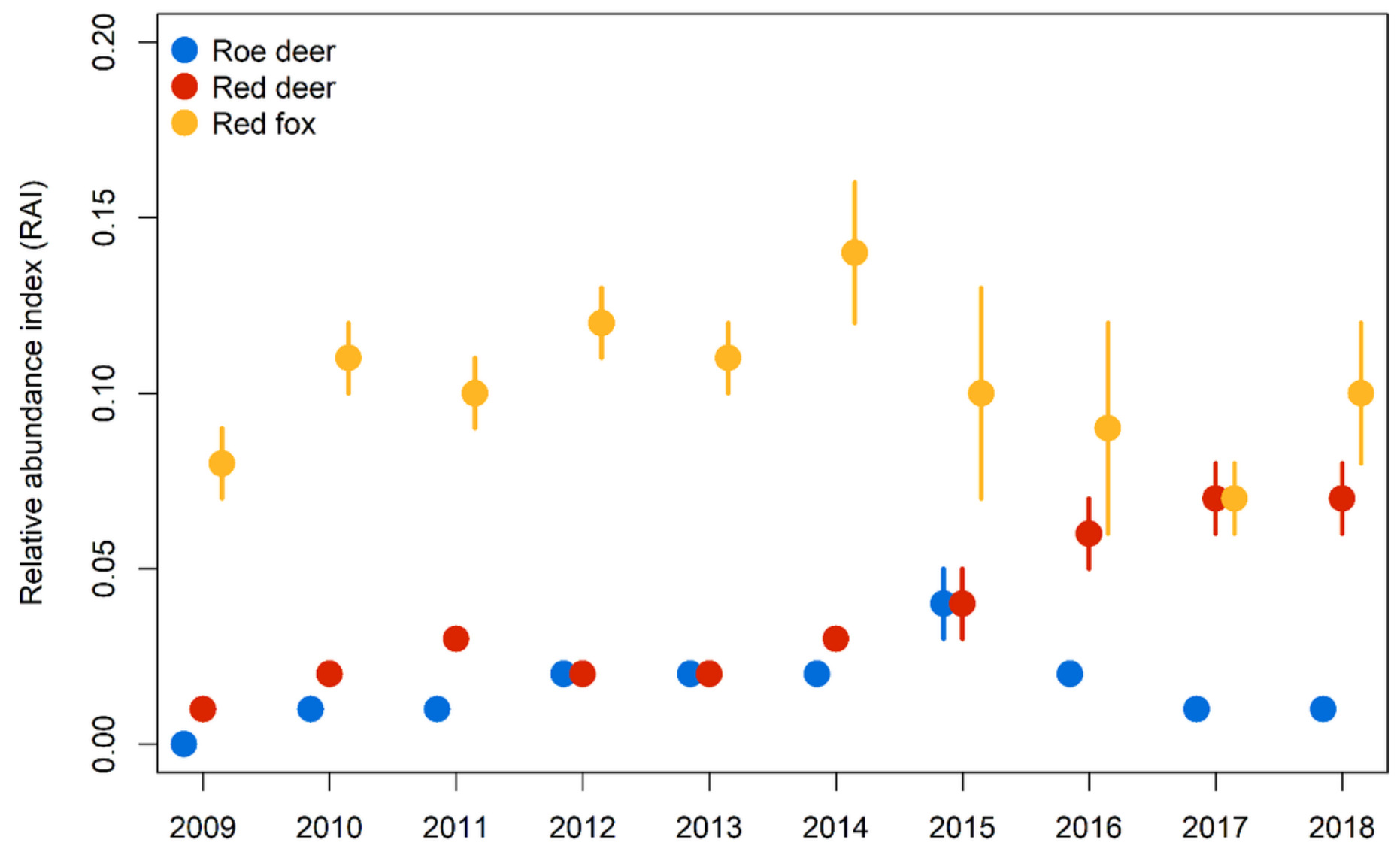

Figure 3

Estimates and standard deviations of the relative abundance index (RAI) of red fox and lynx's prey species roe deer and red deer calculated for the BFNP only.

\section{Supplementary Files}

This is a list of supplementary files associated with this preprint. Click to download.

- Supplemetaryfiguresandtables.pdf 